\title{
Assessing the Curative and Protective Impacts of Select Fungicides for Control of Powdery Mildew of Wheat
}

\author{
Nathan M. Kleczewski, ${ }^{1,2, \dagger}$ Carrie Butts-Willmsmeyer, ${ }^{2}$ and Colin Scanlan ${ }^{1}$ \\ ${ }^{1}$ Department of Plant and Soil Science, University of Delaware, Newark, DE 19716 \\ ${ }^{2}$ Department of Crop Science, University of Illinois, Urbana, IL 61801
}

\begin{abstract}
Powdery mildew, caused by the obligate fungal pathogen Blumeria graminis, has been increasing in incidence and severity on wheat in the Chesapeake Bay region of the mid-Atlantic United States. Although fungicides are used for in-season management of powdery mildew, no studies to date have assessed the ability of these products to control disease after pathogen arrival/infection (curative activity) and the duration of disease control provided after fungicide application (protective activity) under controlled conditions. Five commercially available fungicide products, including Caramba, Stratego YLD, Priaxor, Prosaro, and Trivapro, were applied at either 3 or 5 days after inoculation with B. grami-

fungicide application. All fungicides reduced powdery mildew severity on foliage compared with nontreated controls. Priaxor provided 11 to $18 \%$ less activity than other fungicides when applied curatively. All products provided protective control up to 42 days after inoculation, with Stratego YLD and Priaxor providing the greatest level of control at 68 and $56 \%$, respectively. Our data indicate that different fungicides can have subtle differences in overall efficacy profiles that may translate to improved control or an extended control window in some situations, but all tested products provide very good to excellent control of powdery mildew on wheat.
\end{abstract} nis spores to assess curative activity. In a separate study, protective activity for these fungicides was assessed by applying fungicides and inoculating with $B$. graminis spores the same day and 21 and 42 days after

Keywords: chemical, cereals and grains, disease management, field crops, fungi, techniques

Powdery mildew, caused by the fungus Blumeria graminis f. sp. tritici (syn. Erysiphe graminis), is a foliar disease that is frequently encountered in wheat production systems (Cowger et al. 2012). Like all powdery mildews, $B$. graminis $(\mathrm{Bg})$ is an obligate biotrophic pathogen, requiring a living host to grow and complete its life cycle. Bg is considered a cool season pathogen, favored by temperatures between 15 and $22^{\circ} \mathrm{C}$ and relative humidity between 85 and $100 \%$ (Stromberg 2010). Under favorable conditions, new conidia can be produced 7 to 10 days after initial infection of tissues, resulting in severe epidemics because multiple disease cycles will occur with prolonged optimal conditions. Severe infections rarely result in plant death but can significantly reduce yields (Murray and Brennan 2009).

Soft red winter wheat is a significant crop in the mid-Atlantic United States as a result of the surrounding flour, feed, and burgeoning microbrewery and distillation industries. In 2018, 176,038 ha of soft red winter wheat were planted in Delaware and Maryland, with production valued at $\$ 31,816,000$ USD (U.S. Department of Agriculture National Agricultural Statistics Service 2019). Powdery mildew is an economically important disease of wheat in this region, which has moderate temperatures and high relative humidity during the growing season owing to the Chesapeake Bay and Atlantic Ocean (Sylvester and Kleczewski 2018). Yield losses caused by powdery mildew can exceed 15\% (Bowen et al. 1991). Integrated management of powdery mildew includes the use of resistant varieties, avoiding excessive nutrient applications, and, if needed, the application of a foliar fungicide. Over the last 5 years, producers in Delaware and Maryland have encountered powdery mildew more frequently than in the past, and disease losses have been more common. For example, discussions with local crop consultants indicated that prior to 2011, management of powdery mildew in wheat was not deemed necessary. Since that time, it has developed into an annual issue,

${ }^{\dagger}$ Corresponding author: N. M. Kleczewski; nathank@illinois.edu

The author(s) declare no conflict of interest.

Accepted for publication 22 November 2019.

(C) 2020 The American Phytopathological Society particularly when susceptible varieties are planted near waterways of the Atlantic Ocean. Part of this may be attributed to recent observations that mid-Atlantic populations of $\mathrm{Bg}$ can overcome host resistance genes, commonly included in many commercially available wheat varieties in the region (Cowger et al. 2018). Consequently, a reduction in the number of varieties with effective resistance to powdery mildew has resulted in an increase in the use of foliar fungicides for in-season management of this disease.

There are a limited number and classes of fungicide modes of action available for conventional wheat production. The most common fungicide modes of action used for wheat disease management include those belonging to demethylation inhibitor (DMI), succinate dehydrogenase inhibitor (SDHI), and quinone outside inhibitor (QoI) groups (Mueller et al. 2013). These single-site fungicide active ingredients have translaminar and acropetal activity, but mobility differences exist between groups and active ingredients within groups (Latin 2011). Fungicides containing two and three active ingredients are increasingly common as companies strive to prolong the utility of specific active ingredients and minimize issues related to fungicide resistance development in populations of fungal pathogens. In addition, physical differences in fungicide active ingredients and formulation chemistry may affect overall fungicide performance.

There is wide agreement among extension plant pathologists and agronomists that fungicide efficacy is maximized when applied immediately prior to infection by a fungal pathogen (Mueller et al. 2013). However, this situation is rarely encountered in wheat production systems, where fungicides are often applied on a calendar or growth stage system, regardless of existing disease pressure (Sylvester and Kleczewski 2018; Sylvester et al. 2018; Weisz et al. 2011). Identifying fungicides that provide the largest effective control window may help producers with product selections for managing powdery mildew.

The window of efficacy is related to the ability of a fungicide to stop existing infections and to the duration of time that the fungicide provides effective disease suppression. These terms are better defined as the curative and protective activities of the fungicide, and rarely are these characteristics of fungicides studied in a controlled fashion (Ranzi and Forcelini 2013). Studying the characteristics of fungicides on an obligate pathogen such as $\mathrm{Bg}$ in the field is challenging, as spores must be generated on living plants under controlled 
conditions and a significant amount of space and appropriate facilities are required to produce inoculum. Furthermore, conidia of Bg are inhibited by the presence of free water, making uniform and efficacious inoculation in the field challenging because spray application may reduce inoculation efficacy. For this reason, the majority of fungicide efficacy studies of powdery mildew in the field rely on natural infection; therefore, accurate assessments of the overall fungicide activity window including curative and protective activities are nearly impossible to ascertain (Bowen et al. 1991; Hardwick et al. 1994; Hunger et al. 2014, 2007; Lipps and Madden 1989).

To determine whether differences in fungicide efficacy for controlling powdery mildew can be detected, a set of controlled studies were conducted in growth chambers at the University of Delaware. Studies evaluated five commercially available fungicides used in wheat production systems in the mid-Atlantic for their curative and protective control of powdery mildew on a soft red winter wheat variety adapted to the mid-Atlantic region. Fungicide-free controls were used for comparison.

\section{Materials and Methods}

Experiments were conducted at the University of Delaware Fischer Greenhouse and Growth Chamber Facility located in Newark, Delaware $\left(39.6663^{\circ} \mathrm{N}, 75.74968^{\circ} \mathrm{W}\right)$. There were two sets of studies, a curative study (inoculation with powdery mildew prior to fungicide application) and a protective study (fungicide application prior to inoculation with powdery mildew). Curative and protective experiments were conducted separately and therefore are considered independent studies. Curative studies and production of $\mathrm{Bg}$ conidia were conducted using the highly Bg-susceptible wheat variety Blueboy (Murphy 1967). For the protective studies, the highly Bgsusceptible wheat variety Roane (Griffey et al. 2001) was used because of insufficient quantities of Blueboy seed at the time of the experiment. Seeds were sown at a rate of 25 seeds/pot into $9-\mathrm{cm}^{2}$ pots filled three-quarters full with pasteurized Jiffy Mix (Jiffy Products

Table 1. Curative and protective experiment timelines for fungicide application, inoculation with Blumeria graminis, and disease rating

\begin{tabular}{lll}
\hline & \multicolumn{2}{c}{ Experiment $^{\mathbf{a}}$} \\
\cline { 2 - 3 } Day & Curative & \multicolumn{1}{c}{ Protective } \\
\hline 0 & Inoculate all & $\begin{array}{l}\text { Spray all } \\
\text { Inoculate 0 DAA }\end{array}$ \\
3 & Spray 3 DBA & \\
5 & Spray 5 DBA & \\
10 & Rate all DBA & Rate 0 DAA \\
21 & & Inoculate 21 DAA \\
31 & & Rate 21 DAA \\
42 & & Inoculate 42 DAA \\
52 & & Rate 42 DAA \\
\hline
\end{tabular}

a All studies were conducted two times, with five experimental units per fungicide treatment $\times$ timing combination per experimental run. $\mathrm{DAA}=$ days after fungicide application; DBA = days before fungicide application.
Inc., Lorain, $\mathrm{OH}$ ) and amended with $3 \mathrm{ml}$ of 12:12:12 (N:P:K) slow release Osmocote fertilizer (ICL Everris NA, Columbus, $\mathrm{OH})$. Pots were placed inside a Percival Scientific Inc. (Perry, IA) model 1-60LLVL growth chamber set to provide 400 photosynthetically active radiation light through cool white fluorescent bulbs set on a 12/12-h day/night cycle. Temperature and relative humidity were maintained at $18^{\circ} \mathrm{C}$ and $80 \%$, respectively. To minimize crosscontamination, two chambers were used: one was dedicated to the production of $\mathrm{Bg}$ inoculum and the maintenance of inoculated plants (Bg chamber), and the other was used for the production of disease-free plants and the maintenance of plants prior to inoculation with $\mathrm{Bg}$ (clean chamber). Plants were grown for 10 days after emergence (approximately two leaves exposed) before being used in their respective experiments.

Fungicide and inoculation timing treatments were arranged in a two-factor complete factorial in a generalized randomized block design (GRBD), where experimental run served as the random blocking factor. The two treatment factors were $\mathrm{Bg}$ inoculation timing (5 and 3 days before fungicide application [DBA] for curative; and 0,21 , and 42 days after application [DAA] for protective) and fungicide product. Each treatment combination was replicated five times per experimental run, and each of the two studies consisted of two experimental runs. This resulted in a total of 120 ( 2 runs $\times 2$ timings $\times 6$ treatments $\times 5$ replications) and $180(2$ runs $\times 3$ timings $\times 6$ treatments $\times 5$ replications) experimental units for the curative and protective experiments, respectively.

Powdery mildew treatments. An isolate of $\mathrm{Bg}$ collected from Kent County, Delaware, was provided by DuPont Crop Protection (Wilmington, DE). Pilot studies indicated that it was highly virulent on susceptible wheat varieties (N. Kleczewski, unpublished data). The isolate was maintained by sequential transfers through flats containing 10-day-old wheat seedlings, maintained in a growth chamber (model AR-75L; Percival Scientific Inc.) under the conditions previously described. Deposition chambers, $61 \mathrm{~cm}$ in diameter and $91 \mathrm{~cm}$ deep (large polypropylene trash cans), were used to conduct inoculations. Inoculations were performed by exposing plants to conidia from source plants inoculated 14 days prior with $\mathrm{Bg}$. To inoculate plants, 6 to 10 uninfected seedlings were placed within each chamber in such a way that no leaves were pressed against the sides of the chamber and other pots. Then three source plants of wheat containing actively sporulating $\mathrm{Bg}$ conidia were inverted above each chamber and gently tapped, releasing conidia into the chamber. The spore inoculation rate was approximately 2,225 spores $/ \mathrm{cm}^{2}$ as based on the results of pilot studies in which this method was used to deposit spores into deposition chambers containing glass slides placed at the canopy level. Plants were kept in the chamber for $2 \mathrm{~min}$ to ensure even and complete spore deposition before removal. After inoculation, pots were transferred to the $\mathrm{Bg}$ chamber for incubation. Individual pots were visually rated 10 days postinoculation for percent powdery mildew severity only on the portion of the canopy treated with fungicides. This rating was chosen based on previous studies that indicated that pustules of $\mathrm{Bg}$ developed by 10 days after inoculation.

Table 2. Fungicide products and rates assessed for curative and protective activity against Blumeria graminis in controlled growth chamber studies

\begin{tabular}{|c|c|c|c|c|c|}
\hline Trade name & Manufacturer & Active ingredient(s) & $\begin{array}{l}\text { Mode(s) of action } \\
\text { (FRAC code) }^{\mathbf{a}}\end{array}$ & $\%$ & Rate (liters/ha) \\
\hline Caramba & BASF & Metconazole & DMI (3) & 8.6 & 0.987 \\
\hline \multirow[t]{2}{*}{ Priaxor } & BASF & Fluxapyroxad & SDHI (7) & 14.3 & 0.292 \\
\hline & & Pyraclostrobin & QoI (11) & 28.6 & \\
\hline \multirow[t]{2}{*}{ Prosaro } & Bayer & Prothioconazole & DMI (3) & 19.0 & 0.475 \\
\hline & & Tebuconazole & DMI (3) & 19.0 & \\
\hline \multirow{2}{*}{ Stratego YLD } & Bayer & Prothioconazole & DMI (3) & 10.8 & 0.292 \\
\hline & & Trifloxystrobin & QoI (11) & 32.3 & \\
\hline \multirow[t]{3}{*}{ Trivapro } & Syngenta & Benzovindiflupyr & SDHI (7) & 2.9 & 1.00 \\
\hline & & Azoxystrobin & QoI (11) & 10.5 & \\
\hline & & Propiconazole & DMI (3) & 11.9 & \\
\hline
\end{tabular}

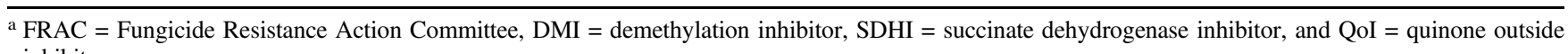
inhibitor. 
To ensure that only tissues exposed to the fungicides were rated, a set of plants were sprayed with water-soluble dye the same day as each fungicide treatment. These plants served as visual guides to ensure that only treated portions of the canopy, and not new, untreated growth, were rated. All plants were also rated for chemical injury (burn, chlorosis, stunting) 7 days after fungicide applications, but none was observed. The curative and protective study timelines are presented in Table 1 for clarity.

Fungicide treatments. Fungicides were applied at the rates listed in Table 2. Fungicides and rates were chosen based on relative use in wheat production in the Chesapeake Bay region as indicated through discussions with producers, retailers, and local extension agents. Applications were made using a DeVries (Hollandale, MN) spray chamber set to deliver fungicides at $206.8 \mathrm{KPa}, 345.72 \mathrm{~cm}$ above the canopy via a single Teejet 80v02 flat fan spray nozzle, resulting in

Table 3. Results of analysis of curative fungicide studies assessing fungicide performance of five commercially formulated fungicides for controlling powdery mildew on wheat using a generalized linear model analyses with log-link function

\begin{tabular}{lrcr}
\hline Effect $^{\mathbf{a}}$ & $\boldsymbol{d} \boldsymbol{f}^{\mathbf{b}}$ & $\boldsymbol{F}$ value & $\boldsymbol{P}$ value \\
\hline Experimental run & 1 & $\mathrm{NA}^{\mathrm{c}}$ & 0.251 \\
Fungicide & 5 & 120.4 & $<0.001$ \\
Inoculation & 1 & 4.0 & 0.047 \\
Fungicide $\times$ inoculation & 5 & 3.6 & 0.005 \\
Residual & 107 & & \\
\hline
\end{tabular}

${ }^{a}$ Random effects of block and experimental run were not significant, and effects were removed from the analysis.

$\mathrm{b} d f=$ degrees of freedom.

${ }^{c} \mathrm{NA}=$ the $F$ value for the experimental run term is not included because random terms are not included in the type III analysis for fixed effects. By contrast, the $P$ value for the experimental run term was calculated using a Wald approach. a 187-liter/ha spray volume. This application method delivered fungicides at rates similar to standard label recommendations. Nontreated controls were treated with water only. Plants were kept at room temperature for $2 \mathrm{~h}$ after spray applications, after which they were transferred either to the $\mathrm{Bg}$ chamber for incubation or to the clean chamber until inoculation.

Statistical analysis. The curative and protective experiments were analyzed separately but using the same model as described below. Preliminary analysis of this GRBD indicated that the errors were non-normal and more closely followed a Poisson distribution. Therefore, a generalized linear mixed model with a log-link function and Poisson distribution was used to analyze both the curative and protective experiments individually. All analyses were conducted in PROC GLIMMIX (SAS 9.4), and the approach employed is similar to that found in Garrett et al. (2004), Madden et al. (2002), and Shah and Madden (2004). Specifically, the full model used was as follows:

$$
\ln \left(E\left[Y_{i j k}\right]\right)=\eta_{i j k}=\mu+R_{i}+T_{j}+F_{k}+R T_{i j}+R F_{i k}+T F_{j k}+R T F_{i j k}
$$

where $\eta_{i j k}=\ln \left(E\left[Y_{i j k}\right]\right)$ is the natural $\log$ of the expected value of the observed disease rating corresponding to the $i$ th experimental run (i.e., the random blocking term), the $j$ th inoculation timing, and the $k$ th fungicide treatment; $\mu$ is the grand population mean; $R_{i}$ is the random effect of the $i$ th experimental run, $\operatorname{NID}\left(0, \sigma_{R}^{2}\right) ; T_{j}$ is the fixed effect of the $j$ th inoculation timing; $F_{k}$ is the fixed effect of the $k$ th fungicide treatment; $R T_{i j}$ is the random interaction between experimental run and inoculation timing, $\operatorname{NID}\left(0, \sigma_{R T}^{2}\right) ; R F_{i k}$ is the random interaction between experimental run and fungicide treatment, $\mathrm{NID}\left(0, \sigma_{R F}^{2}\right) ; T F_{j k}$ is the fixed interaction between inoculation timing and fungicide treatment; and $R T F_{i j k}$ is the random three-way interaction between experimental run, inoculation timing, and fungicide treatment, $\mathrm{NID}\left(0, \sigma_{R T F}^{2}\right)$. Preliminary analyses also indicated that none of the interactions involving the random experimental run term

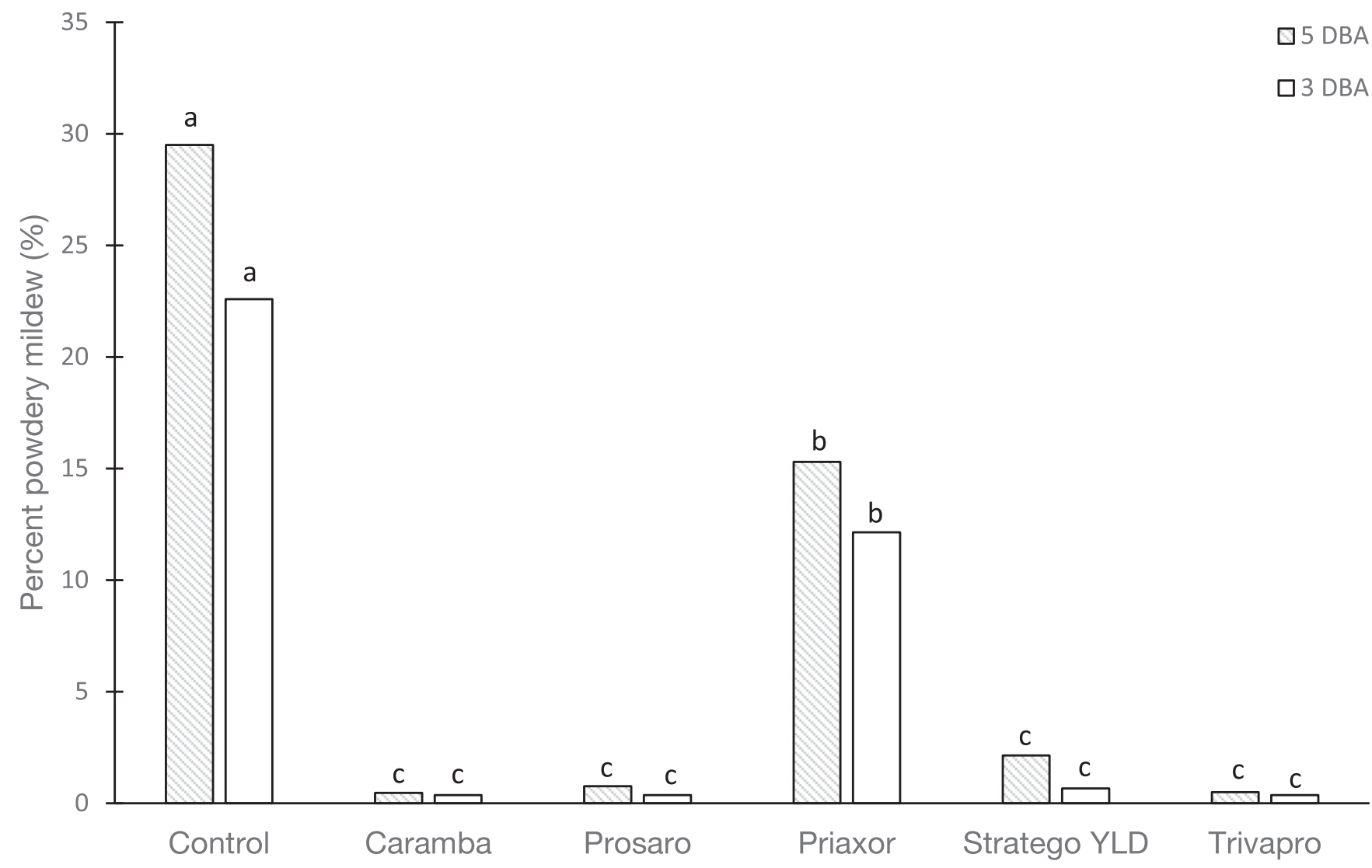

Fig. 1. Mean powdery mildew severities for five fungicides and the nontreated control applied after inoculation of Blueboy wheat. Ratings were made 10 days after inoculation. Different letters indicate significant differences using Tukey's honest significant difference $(\alpha=0.05)$. DBA $=$ days before fungicide application. 
were significant $(P>0.1$ in all cases). Therefore, this model reduced to the following:

$$
\ln \left(E\left[Y_{i j k}\right]\right)=\eta_{i j k}=\mu+R_{i}+T_{j}+F_{k}+T F_{j k}
$$

All $P$ values and other findings presented in the results are based on this reduced model. In the case of a significant interaction between inoculation timing and fungicide treatment, an analysis of simple effects with a multiple comparisons type I error adjustment was employed. Treatment combination means (the least-squares means [LSMEANs] of a particular timing-by-fungicide treatment combination) were separated using Tukey's honest significant difference at $\alpha=0.05$. The percent disease control for the $k$ th fungicide treatment was calculated as follows:

$$
\frac{D_{j C}-D_{j k}}{D_{j C}} \times 100 \%
$$

where $D_{j C}$ is the LSMEAN of the control at the $j$ th inoculation timing and $D_{j k}$ is the LSMEAN of the $k$ th fungicide treatment at the $j$ th inoculation timing. Percent disease control calculations were based on the inverse link scale LSMEANS.

Table 4. Results of analysis of protective fungicide studies assessing fungicide performance of five commercially formulated fungicides for controlling powdery mildew on wheat using a generalized linear model analyses with loglink function

\begin{tabular}{lrcc}
\hline Effect $^{\mathbf{a}}$ & $\boldsymbol{d} \boldsymbol{f}^{\mathbf{b}}$ & $\boldsymbol{F}$ value & $\boldsymbol{P}$ value \\
\hline Experimental run & 1 & $\mathrm{NA}^{\mathrm{c}}$ & 0.245 \\
Fungicide & 5 & 152.1 & $<0.0001$ \\
Inoculation & 2 & 257.4 & $<0.0001$ \\
Fungicide $\times$ inoculation & 10 & 11.8 & $<0.0001$ \\
Residual & 161 & & \\
\hline
\end{tabular}

${ }^{a}$ Random effects of block and experimental run were not significant, and effects were removed from the analysis.

${ }^{\mathrm{b}} d f=$ degrees of freedom.

c NA $=$ the $F$ value for the experimental run term is not included because random terms are not included in the type III analysis for fixed effects. By contrast, the $P$ value for the experimental run term was calculated using a Wald approach.

\section{Results}

Curative studies. A significant interaction was detected between fungicide treatment and inoculation timing for powdery mildew severity in the curative studies $(P=0.005$; Table 3$)$. However, this interaction was attributable to slight and nonsignificant changes in rank among Stratego YLD, Caramba, Prosaro, and Trivapro across the two inoculation timings. Within a particular fungicide treatment, the effect of inoculation timing was found to be nonsignificant in all cases. The percent disease control ranged from 32 to $97 \%$ (Fig. 1). Priaxor provided 32 to $58 \%$ disease control, whereas all other tested fungicides provided $>92 \%$ disease control (Fig. 1).

Protective studies. A significant interaction was detected between fungicide treatment and inoculation timing for powdery mildew severity in the protective studies $(P<0.0001$; Table 4$)$. Overall, the amount of disease control decreased from 0 to 42 DAA; however, the amount of disease control differed by timing and product (Fig. 2). At 0 DAA, percent control was significantly greater in Prosaro (90\%), Stratego YLD (89\%), and Trivapro (79\%) compared with Priaxor (64\%) and Caramba (51\%).

At 21 DAA, percent control was similar among Prosaro (79\%), Stratego YLD (77\%), and Trivapro (67\%). Prosaro and Stratego YLD provided significantly more control than Caramba (58\%), whereas Prosaro provided more control than Priaxor (65\%). Caramba and Priaxor provided similar levels of control (Fig. 2).

At 42 DAA, Stratego YLD (68\%) provided significantly more control than Caramba (39\%), Prosaro (49\%), and Trivapro (43\%) but statistically similar control to Priaxor (56\%). Priaxor provided control similar to Prosaro and Trivapro but greater than Caramba (Fig. 2).

\section{Discussion}

In this work, we demonstrated that although commercially available fungicides commonly used in mid-Atlantic wheat production systems provide control of powdery mildew, there are differences in their curative and protective efficacies that may potentially result in variable overall performance. Our data also indicate that the protective effects of foliar fungicides can still be evident up to 42 days after inoculation with $\mathrm{Bg}$ under growth chamber conditions.

It is generally recognized that protective treatments provide greater control of fungal plant pathogens, as fungicide active ingredients are present on and within plant tissues prior to the arrival of fungal propagules and prevent any damage resulting from infection and

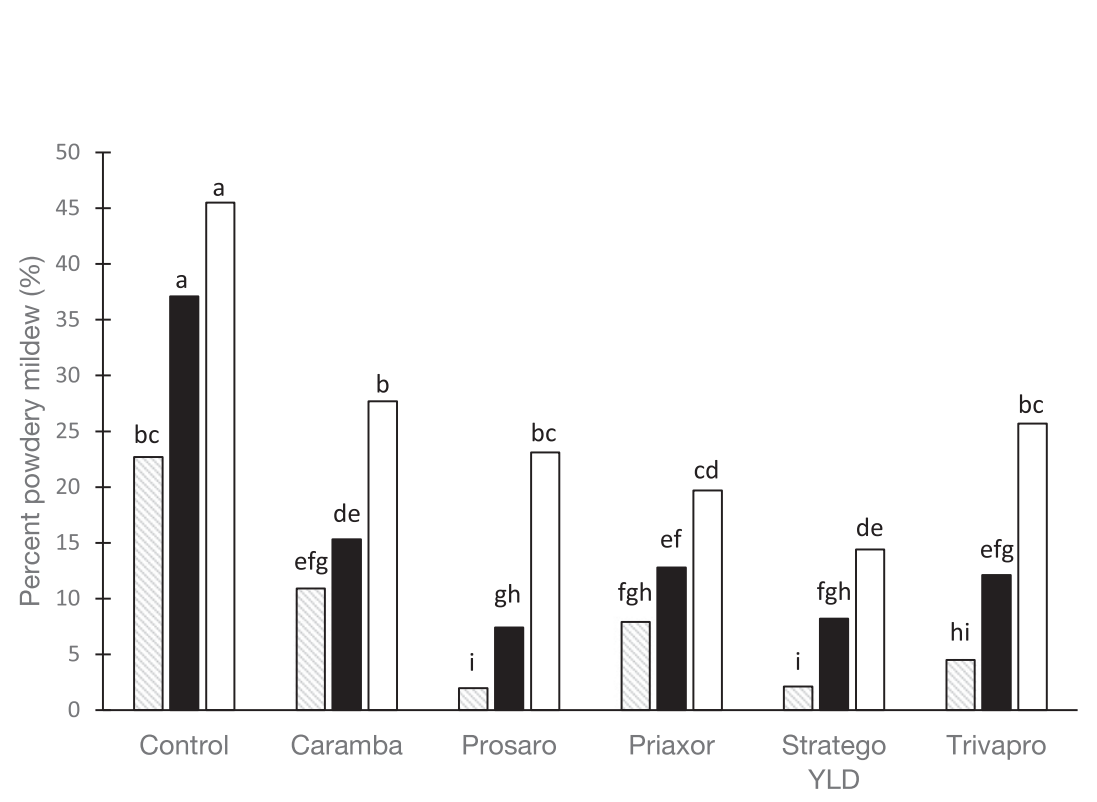

Fig. 2. Mean powdery mildew severities for five fungicides and the nontreated control applied to Roane wheat prior to inoculation. Ratings were made 10 days after inoculation. Different letters indicate significant differences using Tukey's honest significant difference $(\alpha=0.05)$. DAA $=$ days after fungicide application. 
establishment. Our data indicate that all fungicide products tested can provide curative activity of powdery mildew within 5 days of inoculation; however, the amount of control varied with fungicide. Priaxor, the only product tested that does not include a triazole (DMI) active ingredient, provided nearly half as much curative activity as other tested fungicides. These results support those of Ranzi and Forcelini (2013) who assessed the curative effects of DMI, QoI, and DMI+QoI mixtures for controlling Pyrenophora tritici-repentis in wheat. In their research, the application of a DMI or DMI+QoI mixture significantly reduced lesion expansion when applied within 5 days of inoculation, with no effects detected for products containing only QoI active ingredients, thus indicating that DMI active ingredients have better curative activity than QoI fungicides. Given the Priaxor results, we hypothesize that fluxapyroxad, the SDHI active ingredient, does not have the curative activity of the DMIs tested. Although some SDHI (Chen et al. 2014; Duan et al. 2019; He et al. 2017; Veloukas and Karaoglanidis 2012) and QoI (Anesiadis et al. 2003) fungicide active ingredients have limited curative activity in some pathosystems, their efficacy is best realized when applied prophylactically (Mueller et al. 2013). It is important to note that in this study, curative activity of the fungicides was only assessed 5 and 3 days after inoculation. This is a relatively short time for the pathogen to colonize and infect plant tissues. In agricultural systems, curative activity is often associated with making a fungicide application after visualizing signs or symptoms of the pathogen on the plant. In the case of powdery mildew in this study, symptoms of disease started to develop by about 8 days after inoculation, and signs were apparent by 10 days after inoculation. Thus, application of the products 10 days after inoculation would have provided an assessment of curative activity more in line with that typically used in field settings and presents an opportunity for continuing research.

In recent years, the residual or protectant activity of fungicides has been a talking point for many in the agricultural industry. Excellent fungicide residual allows producers to minimize the number of applications made during the growing season. Trivapro, for example, has been advertised as having at least a 42-day residual in field studies (Syngenta Crop Protection 2017). Our data indicate that under the conditions encountered in this study, all tested fungicides significantly reduced the development of powdery mildew at 42 DAA, compared with the control. Of the fungicides tested, Priaxor, Stratego YLD, and Trivapro provided the greatest protective activity. Although the exact reason for the difference in performance in this study is not known, we speculate that it is related to factors associated with the active ingredients (i.e., degradation by the plant, mobility, relative concentration, potency) as well as factors related to inactive ingredients contained within the formulated products. In the field, rainfastness may influence fungicide efficacy (Andersen et al. 2014). Rainfastness can be influenced by several factors, including the amount of rain and when it occurs in relation to fungicide application, product formulation, surfactants, and physical and chemical properties of the fungicide active ingredient (Gaskin and Steele 2009; Hislop 1967; Hunsche et al. 2006; Ivic 2010; Krogh et al. 2003; Vicent et al. 2007). In addition, fungicide efficacy can also be impacted by the quantity and quality of light (Haggi et al. 2002; Kouras-Hadef et al. 2018; Wen et al. 2000), temperature at application, vapor phase activity, plant part being treated, microbial activity, droplet size, and fungicide mobility (Baumeister et al. 2002; Bedos et al. 2010; Leistra and Wolters 2004). In our studies, the impacts of these factors on the degradation of fungicidal components were likely minimized, and overall length of activity was therefore more pronounced than what would be expected in typical field conditions, owing to the lack of overhead watering and use of artificial lighting. Regardless of these limitations, our data indicate that although many of the tested fungicides share common modes of action, there are subtle differences in product efficacy that could affect overall performance and utility for managing powdery mildew in a field setting. Additional field research is needed to better understand the overall longevity and efficacy of these products and how this relates to the duration of control of powdery mildew in wheat.
Powdery mildew is not the only disease encountered in wheat production systems in the mid-Atlantic; other frequently encountered diseases include Parastagonospora leaf and glume blotch, tan spot, and Fusarium head blight (Sylvester and Kleczewski 2018; Sylvester et al. 2018). The overall effectiveness of fungicides in wheat production systems in the region will ultimately depend on the overall efficacy of the chosen fungicide across all commonly occurring, yield-limiting fungal diseases and on product cost. Thus, we suggest that future studies assess product efficacy under controlled conditions similar to those described here to better understand how commonly used fungicides differ in overall efficacy and duration of control across commonly encountered pathosystems.

This work demonstrates that foliar fungicides used in mid-Atlantic wheat production systems are effective for controlling powdery mildew. The effectiveness of products for managing this disease may vary slightly depending on the product used and the timing of application relative to infection. Overall, application of all fungicide products tested in this study significantly reduced powdery mildew relative to nontreated controls. However, future studies are needed to determine the efficacy and profitability of using these products in the field.

\section{Acknowledgments}

We thank Dr. Christina Cowger, Dr. Darcy Telenko, and Zach Duray for reviewing prior drafts of this manuscript, as well as four anonymous reviewers for insightful comments. We also thank the University of Delaware staff for assisting with growth chamber set up and maintenance.

\section{Literature Cited}

Andersen, K., Morris, L., Derksen, R., Madden, L., and Paul, P. 2014. Rainfastness of prothioconazole + tebuconazole for Fusarium head blight and deoxynivalenol management in soft red winter wheat. Plant Dis. 98:1398-1406.

Anesiadis, T., Karaoglanidis, G., and Tzavella-Klonari, K. 2003. Protective, curative and eradicant activity of the strobilurin fungicide azoxystrobin against Cercospora beticola and Erysiphe betae. J. Phytopathol. 151:647-651.

Baumeister, M., Steep, M., Dieckmann, S., Melzer, O., Kloppel, H., Jurling, H. and Bender, L. 2002. Transfer of the fungicide vinclozolin from treated to untreated plants via volatilization. Chemosphere 48:75-82.

Bedos, C., Rousseau-Djabri, M. F., Loubet, B., Durand, B., Flura, D., Briand, O., and Barriuso, E. 2010. Fungicide volatilization measurements: Inverse modeling, role of vapor pressure, and state of foliar residue. Environ. Sci. Technol. 44:2522-2528

Bowen, K. L., Everts, K. L., and Leath, S. 1991. Reduction in yield of winter wheat in North Carolina due to powdery mildew and leaf rust. Phytopathology 81 : 503-511.

Chen, F., Han, P., Liu, P., Si, N., Liu, J., and Liu, X. 2014. Activity of the novel fungicide SYP-Z048 against plant pathogens. Sci. Rep. 4:6473.

Cowger, C., Mehra, L., Arellano, C., Meyers, E., and Murphy, J. P. 2018. Virulence differences in Blumeria graminis f. sp. tritici from the central and eastern United States. Phytopathology 108:402-411.

Cowger, C., Miranda, L., Griffey, C., Hall, M., Murphy, J., Maxwell, J., and Sharma, I. 2012. Wheat powdery mildew. Pages 84-119 in: Disease Resistance in Wheat. CABI, Oxfordshire, UK.

Duan, Y., Xiu, Q., Li, H., Li, T., Wang, J., and Zhou, M. 2019. Pharmacological characteristics and control efficacy of a novel SDHI fungicide pydiflumetofen against Sclerotinia sclerotiorum. Plant Dis. 103:77-82.

Garrett, K., Madden, L., Hughes, G., and Pfender, W. 2004. New applications of statistical tools in plant pathology. Phytopathology 94:999-1003.

Gaskin, R. E., and Steele, K. D. 2009. A comparison of sticker adjuvants for their effects on retention and rainfastening of fungicide sprays. N. Z. Plant Prot. 62: 339-342.

Griffey, C., Starling, T., Price, A., Sisson, W., Das, M., Pridgen, T., Vaughn, M., Rohrer, W., and Brann, D. 2001. Registration of 'Roane' wheat. Crop Sci. 41:1359.

Haggi, E., Bertolotti, S., Miskoski, S., Amat-Guerri, F., and Garcia, N. 2002. Environmental photodegradation of pyrimidine fungicides: Kinetics of the visible-light-promoted interactions between riboflavin and 2-amino-4hydroxy-6-methylpyrimidine. Can. J. Chem. 80:62-67.

Hardwick, N. V., Jenkins, J. E. E., Collins, B., and Groves, S. J. 1994. Powdery mildew (Erisiphe graminis) on winter wheat: Control with fungicides and the effects on yield. Crop Prot. 13:93-98.

He, L., Cui, K., Ma, D., Shen, R., Huang, X., Jiang, J., Mu, W., and Liu, F. 2017 Activity, translocation, and persistence of isopyrazam for controlling cucumber powdery mildew. Plant Dis. 101:1139-1144.

Hislop, E. C. 1967. Observations on vapour phase activity of some foliage fungicides. Ann. Appl. Biol. 60:265-279.

Hunger, R. M., Grachet, N. G., Olson, B. R., Walker, R., and Edwards, J. H. 2014 Management of powdery mildew and leaf spot diseases on winter wheat in Oklahoma, 2013. Plant Dis. Manage. Rep. 8:CF032. 
Hunger, R. M., Kader, K. A., Edwards, J. H., and Walker, R. 2007. Effect of fungicides on powdery mildew and leaf rust of hard red winter wheat in Oklahoma, 2007. Plant Dis. Manage. Rep. 2:CF012.

Hunsche, M., Bringe, K., Schmitz-Eiberger, M., and Noga, G. 2006. Leaf surface characteristics of apple seedlings, bean seedlings and kohlrabi plants and their impact on the retention and rainfastness of mancozeb. Pest Manag. Sci. 62:839-847.

Ivic, D. 2010. Curative and eradicative effects of fungicides. Online publication. IntechOpen. doi: 10.5772/13766.

Kouras-Hadef, S., Hamdache, S., de Sainte-Claire, P., Sleiman, M., Jaber, F., and Richards, C. 2018. Light induced degradation of the fungicide thiophanatemethyl in water: Formation of a sensitizing photoproduct. J. Photochem. Photobiol. A 360:262-269.

Krogh, K. A., Halling-Sorensen, B., Mogensen, B. B., and Vejrup, K. V. 2003. Environmental properties and effects of nonionic surfactant adjuvants in pesticides: A review. Chemosphere 50:871-901.

Latin, R. 2011. A Practical Guide to Turfgrass Fungicides. American Phytopathological Society, St. Paul, MN.

Leistra, M., and Wolters, A. 2004. Computations on the volatilisation of the fungicide fenpropimorph from plants in a wind tunnel. Water Air Soil Pollut. 157:133-148.

Lipps, P. E., and Madden, L. V. 1989. Effect of fungicide application timing on control of powdery mildew and grain yield of winter wheat. Plant Dis. 73: 991-994.

Madden, L., Turechek, W., and Nita, M. 2002. Evaluation of generalized linear mixed models for analyzing disease incidence data obtained in designed experiments. Plant Dis. 86:316-325.

Mueller, D. S., Wise, K. A., Dufault, N. S., Bradley, C. A., and Chilvers, M. I. 2013. Fungicides for Field Crops. American Phytopathological Society, St. Paul, MN.

Murphy, C. F. 1967. Registration of Blueboy wheat (Reg. No. 456). Crop Sci. 7:82.

Murray, G. M., and Brennan, J. P. 2009. The Current and Potential Costs From Wheat Diseases in Australia. Grains Research and Development Cooperation, Canberra, Australia.
Ranzi, C., and Forcelini, C. A. 2013. Curative sprays of fungicides and their effect on lesion expansion of the wheat tan spot [Aplicação curativa de fungicidas e seu efeito sobre a expansão de lesão da mancha-amarela do trigo]. Cienc. Rural 43:1576-1581.

Shah, D., and Madden, L. 2004. Nonparametric analysis of ordinal data in designed factorial experiments. Phytopathology 94:33-43.

Stromberg, E. L. 2010. Powdery mildew. Pages 43-45 in: Compendium of Wheat Diseases and Pests, vol. 3. W. W. Bockus, R. L. Bowden, R. M. Hunger, W. L. Morill, T. D. Murray, and R. W. Smiley, eds. American Phytopathological Society, St. Paul, MN.

Sylvester, P. N., and Kleczewski, N. M. 2018. Evaluation of foliar fungicide programs in mid-Atlantic winter wheat production systems. Crop Prot. 103: 103-110.

Sylvester, P. N., Lana, F. D., Mehl, H. L., Collins, A. A., Paul, P. A., and Kleczewski, N. M. 2018. Evaluating the profitability of foliar fungicide programs in midAtlantic soft-red winter wheat production. Plant Dis. 102:1627-1637.

Syngenta Crop Protection. 2017. Trivapro corn sell sheet. http://www.syngentaus.com

U.S. Department of Agriculture National Agricultural Statistics Service. 2019 Small grains summary. https://www.nass.usda.gov

Veloukas, T., and Karaoglanidis, G. S. 2012. Biological activity of the succinate dehydrogenase inhibitor fluopyram against Botrytis cinerea and fungal baseline sensitivity. Pest Manag. Sci. 68:858-864.

Vicent, A., Armengol, J., and Garcia-Jimenez, J. 2007. Rain fastness and persistence of fungicides for control of Alternaria brown spot of citrus. Plant Dis. 91:393-399.

Weisz, R., Cowger, C., Ambrose, G., and Gardner, A. 2011. Multiple mid-Atlantic field experiments show no economic benefit to fungicide application when fungal disease is absent in winter wheat. Phytopathology 101:323-333.

Wen, C., Hasegawa, K., Kanbara, T., Kagaya, S., and Yamamoto, T. 2000. Visible light-induced catalytic degradation of iprobenfos fungicide by poly(3octylthiophene-2,5-diyl) film. J. Photochem. Photobiol. A 133:59-66. 